\title{
Clinical relevance of targeted exome sequencing in patients with rare syndromic short stature
}

\author{
Gilyazetdinov Kamil ${ }^{1,3}$ (]) Ju Young Yoon ${ }^{2}$, Sukdong Yoo ${ }^{2}$ and Chong Kun Cheon ${ }^{2,3^{*}}$ (D)
}

\begin{abstract}
Background: Large-scale genomic analyses have provided insight into the genetic complexity of short stature (SS); however, only a portion of genetic causes have been identified. In this study, we identified disease-causing mutations in a cohort of Korean patients with suspected syndromic SS by targeted exome sequencing (TES).

Methods: Thirty-four patients in South Korea with suspected syndromic disorders based on abnormal growth and dysmorphic facial features, developmental delay, or accompanying anomalies were enrolled in 2018-2020 and evaluated by TES.

Results: For 17 of 34 patients with suspected syndromic SS, a genetic diagnosis was obtained by TES. The mean SDS values for height, IGF-1, and IGFBP-3 for these 17 patients were $-3.27 \pm 1.25,-0.42 \pm 1.15$, and $0.36 \pm 1.31$, respectively. Most patients displayed distinct facial features (16/17) and developmental delay or intellectual disability (12/17). In 17 patients, 19 genetic variants were identified, including 13 novel heterozygous variants, associated with 15 different genetic diseases, including many inherited rare skeletal disorders and connective tissue diseases (e.g., cleidocranial dysplasia, Hajdu-Cheney syndrome, Sheldon-Hall, acromesomelic dysplasia Maroteaux type, and microcephalic osteodysplastic primordial dwarfism type II). After re-classification by clinical reassessment, including family member testing and segregation studies, $42.1 \%$ of variants were pathogenic, $42.1 \%$ were likely pathogenic variant, and $15.7 \%$ were variants of uncertain significance. Ultra-rare diseases accounted for 12 out of 15 genetic diseases (80\%).
\end{abstract}

Conclusions: A high positive result from genetic testing suggests that TES may be an effective diagnostic approach for patients with syndromic SS, with implications for genetic counseling. These results expand the mutation spectrum for rare genetic diseases related to SS in Korea.

Keywords: Mutation, Short stature, Syndrome, Targeted exome sequencing

\section{Introduction}

Height is a polygenic trait [1]; although more than $80 \%$ of height variation can be explained by genetic factors, the contribution of environmental factors is clearly established [2]. The identification of novel rare genetic causes of short stature (SS) is challenging. Syndromic SS is often

\footnotetext{
*Correspondence: chongkun@pusan.ac.kr

${ }^{2}$ Division of Pediatric Endocrinology, Department of Pediatrics, Pusan National University Children's Hospital, Yangsan, Korea

Full list of author information is available at the end of the article
}

associated with monogenic disorders. Over 700 common variants that explain $20 \%$ of height variation in the normal population as well as 83 rare and low-frequency coding variants explaining an additional $1.7 \%$ of variation have been reported [3, 4]. In addition, genetic variants that are outside the reach of the most statistically powered association studies [5] are considered to contribute to the missing heritability of many human traits, including common variants and rare variants of small to modest effect, or a combination of both [6].

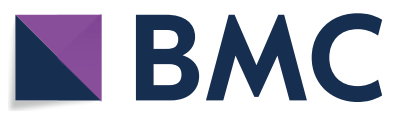

(C) The Author(s) 2021. Open Access This article is licensed under a Creative Commons Attribution 4.0 International License, which permits use, sharing, adaptation, distribution and reproduction in any medium or format, as long as you give appropriate credit to the original author(s) and the source, provide a link to the Creative Commons licence, and indicate if changes were made. The images or other third party material in this article are included in the article's Creative Commons licence, unless indicated otherwise in a credit line to the material. If material is not included in the article's Creative Commons licence and your intended use is not permitted by statutory regulation or exceeds the permitted use, you will need to obtain permission directly from the copyright holder. To view a copy of this licence, visit http://creativecommons.org/licenses/by/4.0/. The Creative Commons Public Domain Dedication waiver (http://creativeco mmons.org/publicdomain/zero/1.0/) applies to the data made available in this article, unless otherwise stated in a credit line to the data. 
The identification of pathogenic mutations has important implications; for example, a genetic diagnosis avoids unnecessary investigations and treatment, allows appropriate genetic counseling and the identification of comorbidities in syndromic SS, and may also lead to the earlier initiation of therapy [7]. In particular, if SS is related to dysmorphic features, a syndromic condition should be suspected and a genetic test should be conducted [8]. Exome sequencing methods, such as targeted exome sequencing (TES) and whole exome sequencing (WES), can be useful in clinical practice for the genetic diagnosis of diseases associated with SS $[9,10]$. In a recent study, a potential genetic etiology in children with SS was identified in 41 patients (36\%), mostly by TES/WES [11]. However, the diagnostic yield for genetic SS is highly dependent on the sequencing methods, population, availability of additional family members, and definition of a high-likelihood diagnosis [12]. In 2017, in a mutation analysis of 13 families with undiagnosed syndromic SS or overgrowth, we obtained a high diagnostic yield (46.2\%) [13]. In this study, we used TES to evaluate diseasecausing mutations in 34 Korean patients with suspected genetic SS and characterized the clinical features of this population. We report rare genetic diseases newly associated with SS.

\section{Material and methods}

\section{Patients}

This retrospective cohort study was conducted between January 2018 and January 2020. Thirty-four patients with suspected syndromic disorders based on abnormal growth (height SDS $<-2.0$ for age and sex within South Korea), and distinct facial features, developmental delay, or accompanying anomalies were recruited from Pusan National University Children's Hospital, Yangsan, South Korea. This phenotyping was performed by one single medical geneticist and then entered into the phenotype database. This was done upon the patient's initial presentation to the clinic before results from genetic testing had returned. Traditional genetic methods such as karyotyping, chromosomal microarray (CMA), or single-gene analysis were performed based on the initial clinical assessments in most cases, but no causative genetic defect was found. In this study, we applied TES to only the probands with undiagnosed SS. All parents except for the parents of 2 patients were available to conduct familial sanger analysis after. A total of 34 patients with SS from 33 families were enrolled.

\section{Collected data}

The following clinical data were collected: term and birth measurements (length, weight and head circumference), postnatal growth parameters, major developmental milestones, and neurological symptoms at the time of the diagnosis. Each patient was subjected to endocrine evaluation [thyroid function test, insulin-like growth factor 1 (IGF-1) and insulin-like growth factor-binding protein 3 (IGFBP-3)], routine laboratory tests (complete blood count, erythrocyte sedimentation rate, and liver and renal function tests), and X-ray to determine bone age. Growth hormone deficiency (GHD) was defined as growth hormone peak value $<10 \mathrm{ng} / \mathrm{ml}$ on the arginine and clonidine stimulation test. We also obtained patients' family and past history, including parental height, calculation of mid-parental height (MPH), birth history, previous medication, illness, surgery, and nutrition. For girls, $\mathrm{MPH}$ was (maternal height + paternal height $-13 \mathrm{~cm}$ )/2 and that for boys was (maternal height + paternal height $+13 \mathrm{~cm}$ ) $/ 2$. Previous growth velocity was evaluated and body proportion was determined by measuring arm span and sitting height. The sitting height was subtracted from the patient's standing height to obtain the lower body segment value. Ultra-rare diseases were defined as disorders that occur with a prevalence of below 1 in 2,000,000 [14].

\section{DNA and data collection}

This study was performed in accordance with the Declaration of Helsinki. Informed consent was obtained from all study participants before blood was drawn. A one-off blood sample was collected for DNA extraction. Demographic factors and other clinical features including facial dysmorphism and accompanying body anomalies were collected from clinical records.

\section{Targeted exome sequencing}

Pure genomic DNA was isolated from peripheral blood leukocytes using the QIAamp DNA Blood Midi Kit (Qiagen, Hilden, Germany) according to the manufacturer's protocols. The proband was evaluated using the TruSight One Sequencing Panel (Illumina, Inc., San Diego, CA, USA), which includes 125,395 probes targeting a $12 \mathrm{Mb}$ region comprehensively covering the exonic regions of 4813 genes-OMIM associated genes with clinical significance. The probe size was 80 -mer, targeting libraries of nearly $500 \mathrm{bp}$, enriching 350-650 bases centered symmetrically at the midpoint of the probe. The captured target regions were sequenced using the Illumina HiSeq2500 sequencer (Illumina, Inc.) according to the manufacturer's instructions. A mean coverage of 105.49X was achieved, and $95.21 \%$ of targeted bases were read $>20$ times by exome capture and sequencing. Alignments and variant calling were performed using on-instrument software, followed by filtering and customized reporting for specific genes by the analysis of imported sequence data using VariantStudio. Variants in the dbSNP135 and TIARA databases 
for the Korean population and variants with minor allele frequencies of $>0.5 \%$ in the 1000 Genomes database were excluded from further analyses. Only functional variants were selected as pathogenic mutations. The functional annotation tools SIFT (http://sift.jcvi.org/), PolyPhen2 (http://genetics.bwh.harvard.edu/pph2/), and MutationTaster (http://www.mutationtaster.org/) were used to evaluate novel mutations and variants of uncertain significance (VUS). Variants were classified according to the methods recommended by the American College of Medical Genetics and Genomics. Mutation nomenclature was based on the cDNA reference sequences for RUNX2 (NM_001024630), NOTCH2 (NM_024408.3), SLC6A8 (NM_005629.3), RPS6KA3 (NM_ 004586.2), IGFALS (NM_004970.2), TNNT3 (NM_006757.3), NPHP3 (NM_153240.4), ARID1B (NM_020732.3), NPR2 (NM_003995.3), KMT5B (NM_017635.4), CC2D1A (NM_017721.4), SMC3 (NM_005445.3), MEIS2 (NM_170674.4), PCNT (NM_006031.5), NOTCH2 (NM_ 024408.3), and MED13L (NM_015335.4).

\section{Validation by Sanger sequencing}

Sanger sequencing was used to confirm the causative variants. All causative variants were sequenced bi-directionally using an ABI PRISM 3.1 Big Dye Terminator Kit (Applied Biosystems, Foster City, CA, USA). The sequencing products were resolved on an ABI PRISM 3130XL sequencer (Applied Biosystems) and the chromatograms were analyzed using Sequencer 4.9 (Gene Codes, Ann Arbor, MI, USA).

\section{Protein structural modeling}

Among cases with genetically confirmed syndromic SS, protein structural modeling was performed for $\mathrm{NOTCH} 2$ and $M E D 13 L$ variants. The crystal structures of the domains from wild-type NOTCH 2 and $M E D 13 L$ were generated using SWISS-MODEL [https://swissmodel.expasy. org/]. Structural images were generated using PyMOL version 29 [https://pymol.org/2/].

\section{Statistics}

All statistical analyses were performed using the R studio software (version 3.5.1). Mann-Whitney U-test was performed for continuous variables. Fisher's exact test was performed for categorical variables according to its characteristics. Odds ratio and confidential interval were calculated for variables.

\section{Results}

\section{Clinical and genetic features of individuals with short stature}

The auxological profiles, hormone results, and additional clinical features of the patients are listed in Table 1. The mean height SDS of 17 genetically diagnosed patients at the time of the hospital visit was $-3.27 \pm 1.25$. The mean SDS values for IGF-1 SDS and IGFBP-3 at diagnosis were $-0.42 \pm 1.15$ and $0.36 \pm 1.31$, respectively. A GHD was identified in $23.5 \%$ (4/17) of patients who underwent a GH provocation test. Two of the 17 (11.7\%) patients were small for gestational age (SGA) at birth. Most patients (16/17) exhibited distinct facial features at least one or two of these, including macrocephaly or microcephaly, hypertelorism, small chin, sparse hair, triangular face, synophrys, epicanthal fold, and low-set ears. Developmental delay (DD) or intellectual disability (ID) was noted in 12 of 17 patients. Other accompanying anomalies included skeletal anomalies (9/17), microcephaly $(9 / 17)$, congenital heart disease (4/17), brain anomaly $(2 / 17)$, corneal opacity (1/17), and hernia (1/17).

The previous clinical assessments and final diagnosis for each patient are shown in Table 2. For 5 of 17 patients (K3, K5, K7, K11, and K15), it was difficult to identify a recognizable disease or syndrome based on clinical characteristics alone. These five patients were diagnosed with cerebral creatine deficiency syndrome (K3), acid-labile subunit deficiency (K5), Meckel syndrome type 7 (K7), mental retardation, autosomal recessive Type3 (K11), and Hajdu-Cheney syndrome (HCS) (K15) by TES.

Three (17.6\%) patients (K1, K4, and K10) had suspected syndromes, such as Noonan syndrome, based on facial and clinical features, but no mutations were identified by Sanger sequencing of PTPN11, SOS1, RAF1, and KRAS. Patient K1 showed dysmorphic facial features, such as relative macrocephaly, broad nasal bridge, deep philtrum, hypertelorism, low set ears, strabismus, pectus excavatum, delayed teeth and closure (ossification) of the fontanelle, and GHD. The patient was confirmed to have cleidocranial dysplasia with a de novo missense mutation, c.578G >A (p.R193Q), in RUNX2. Patient K4 displayed dysmorphic facial features, such as hypertelorism, epicanthal fold, broad nose, anteverted nares, short philtrum, large mouth, thick/everted lips, large ears, thoracolumbar spondylosis, pectus excavatum, speech delay, and severe ID. A novel hemizygous missense variant, c.1606G $>\mathrm{T}$ (p.V536F), in RPS6KA3 was identified in a patient with Coffin-Lowry syndrome. Patient K10 displayed severe SS (-4.27 SDS). He showed dysmorphic facial features, such as a high forehead, plagiocephaly, hypertelorism, macrocephaly, prominent philtrum, low and posterior rotated ears, short neck, low hairline, round shoulder, broad chest, congenital heart defect, and DD. A genetic analysis revealed a de novo novel frameshift mutation (p.L808Wfs*50) in KMT5B, resulting in mental retardation, autosomal dominant type 51.

Patient K2 was initially suspected of having Turner syndrome with a severe SS ( -3.06 SDS), dysmorphic facial 


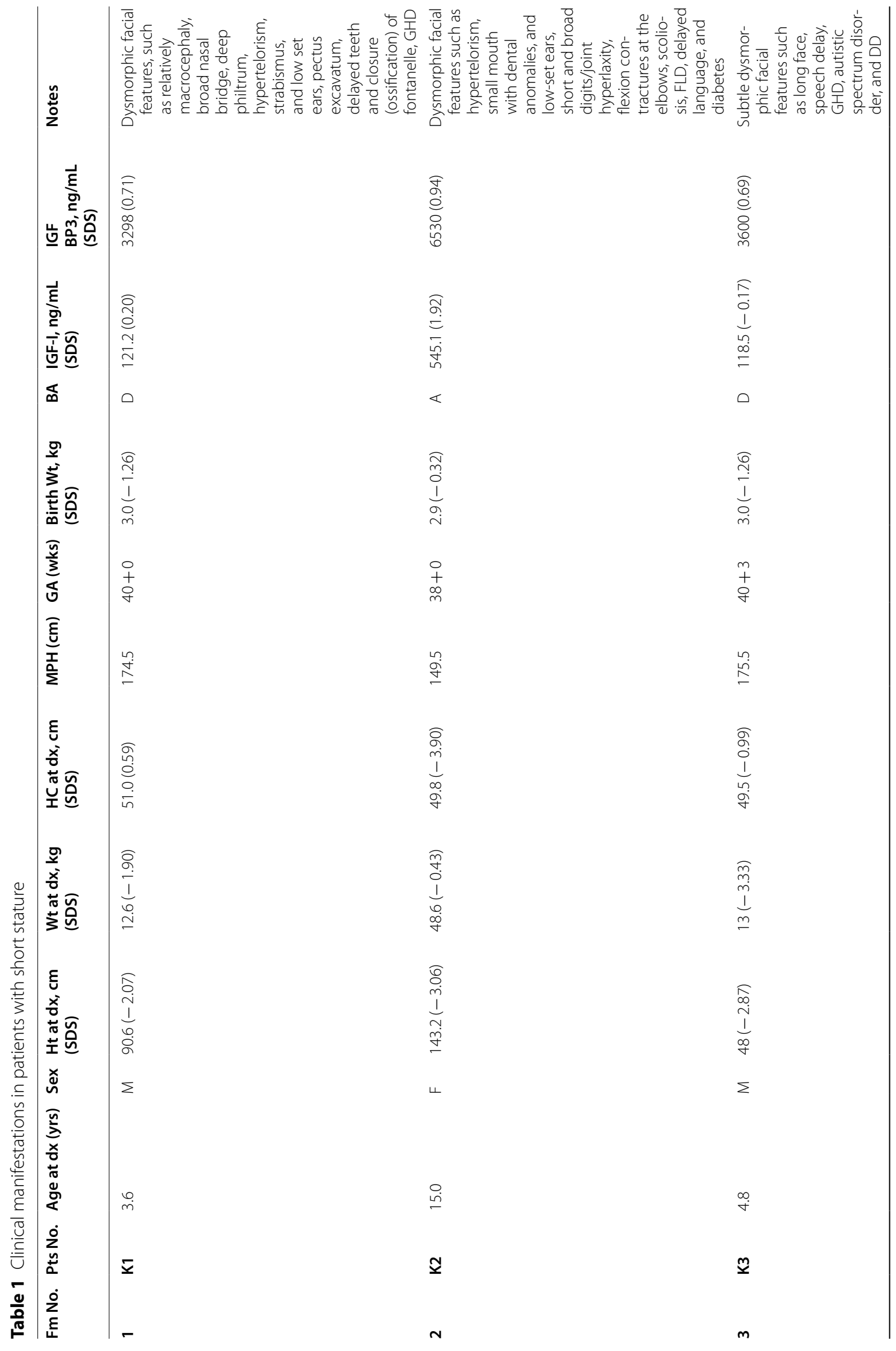




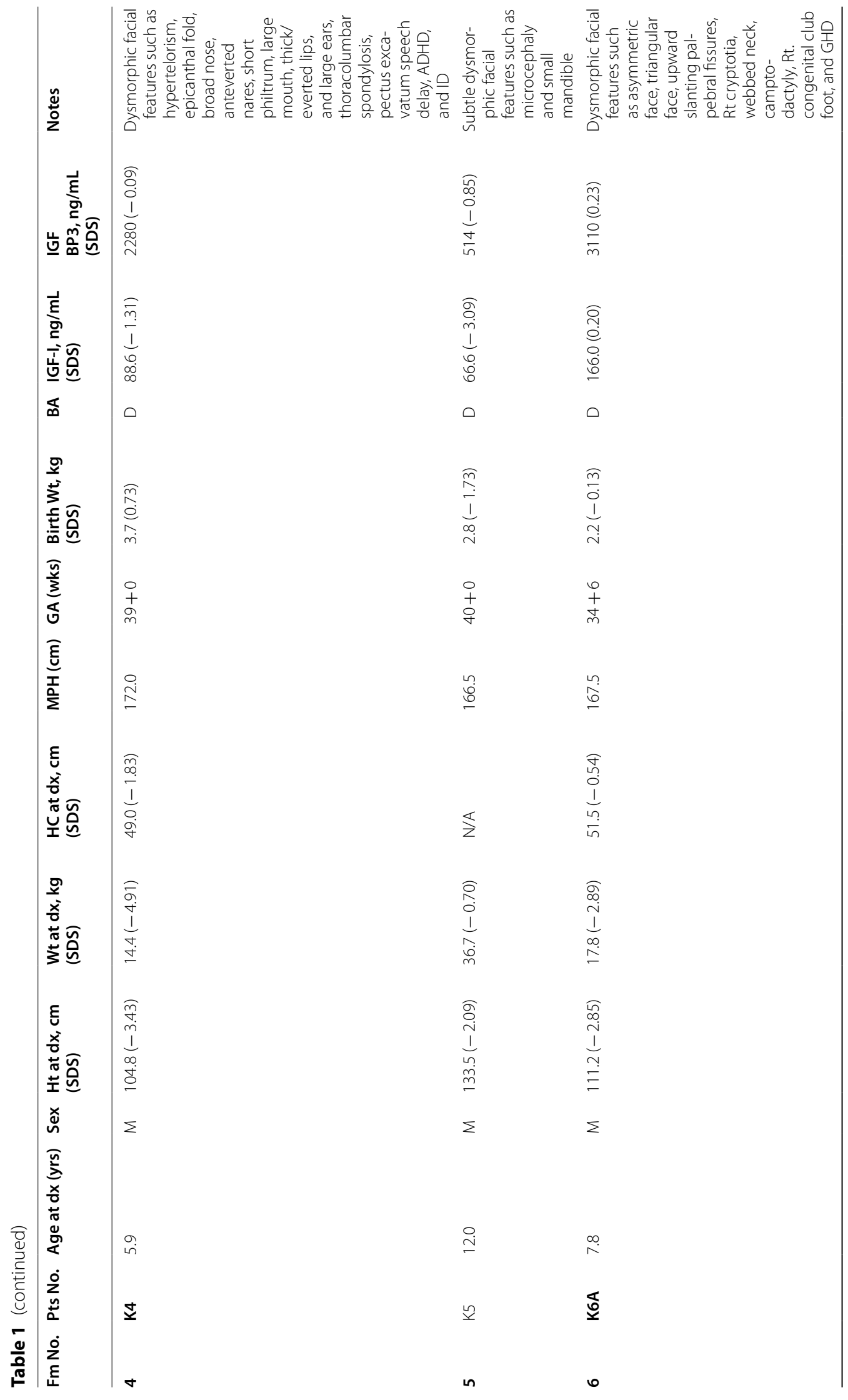




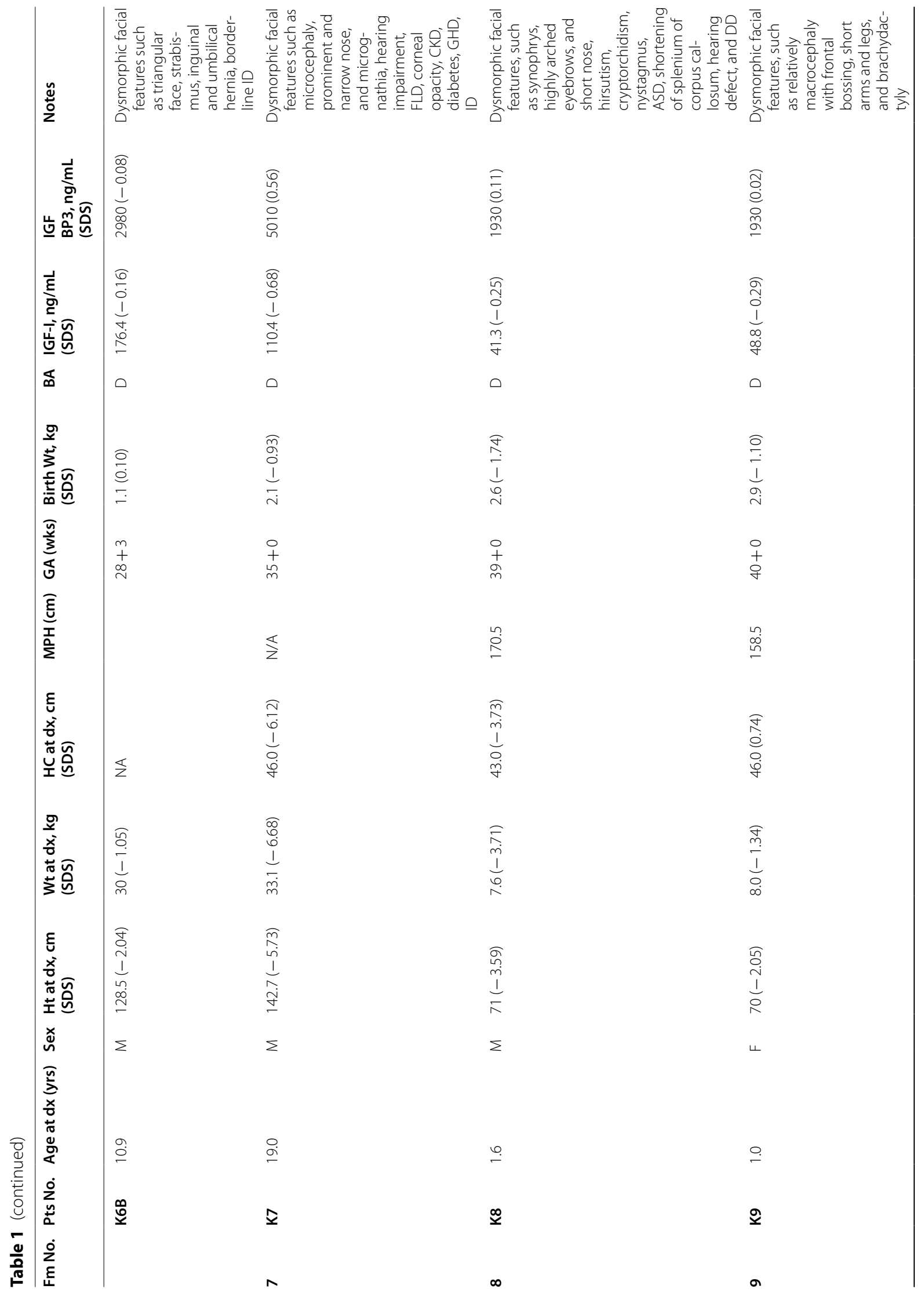




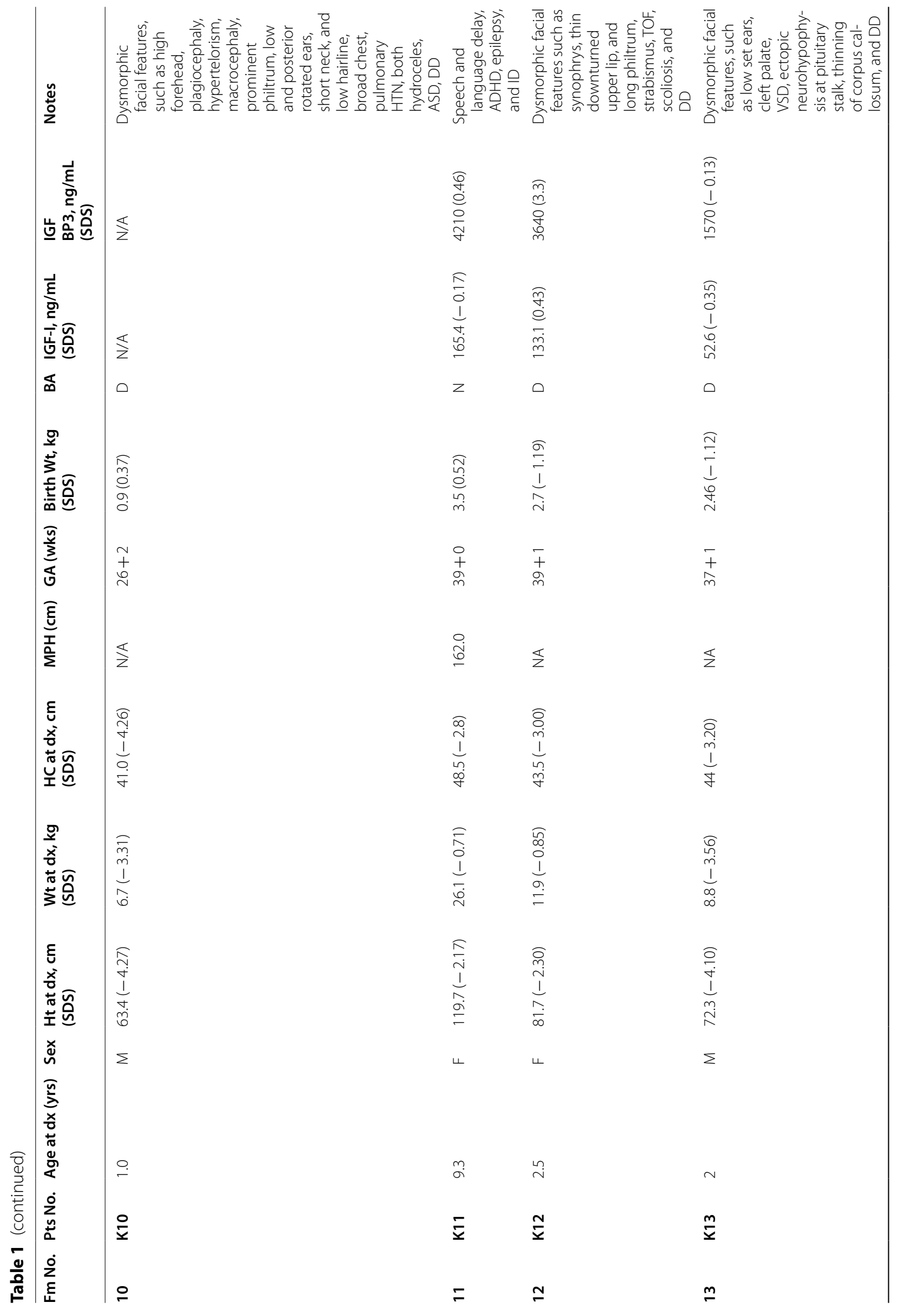




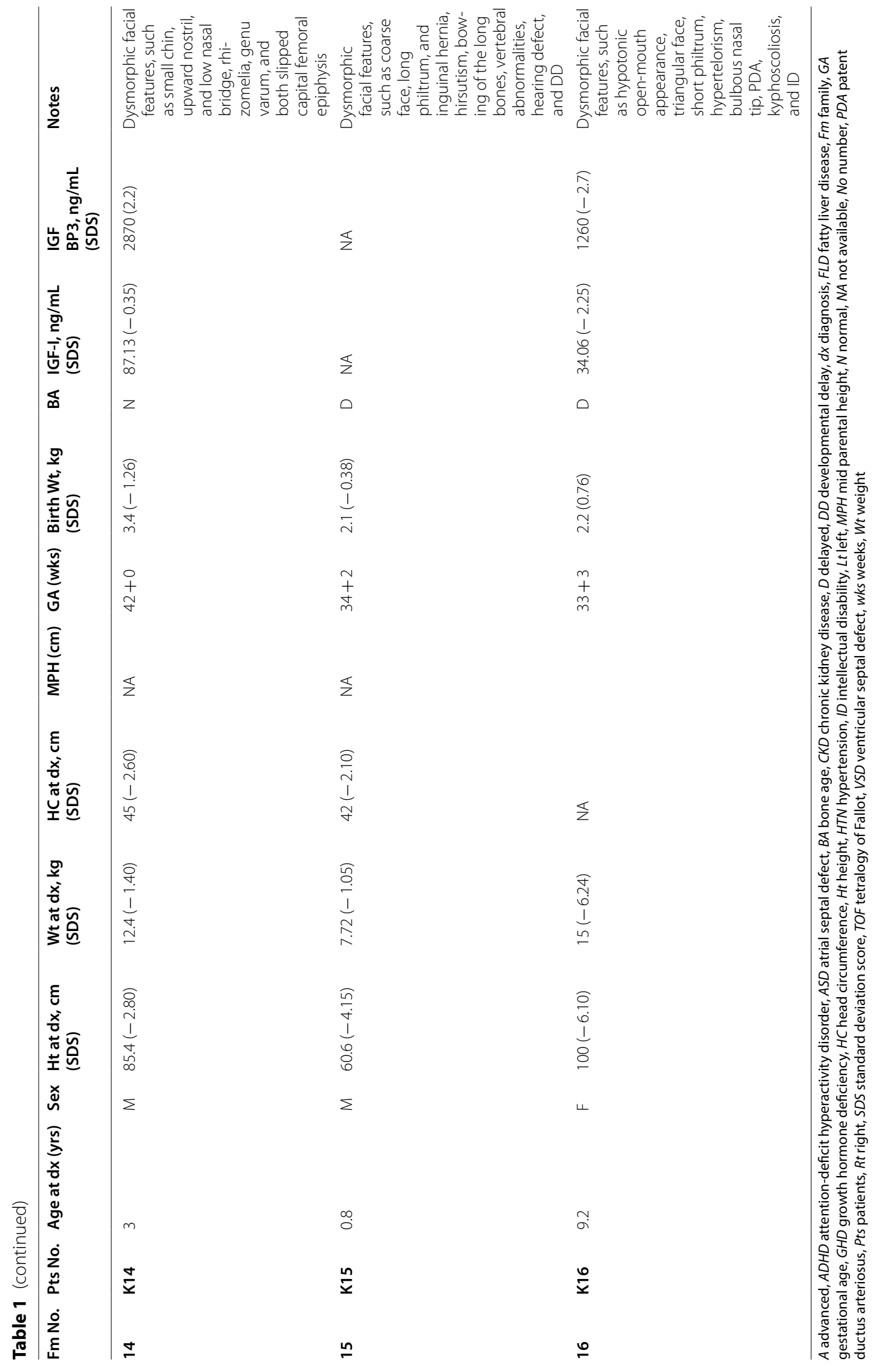




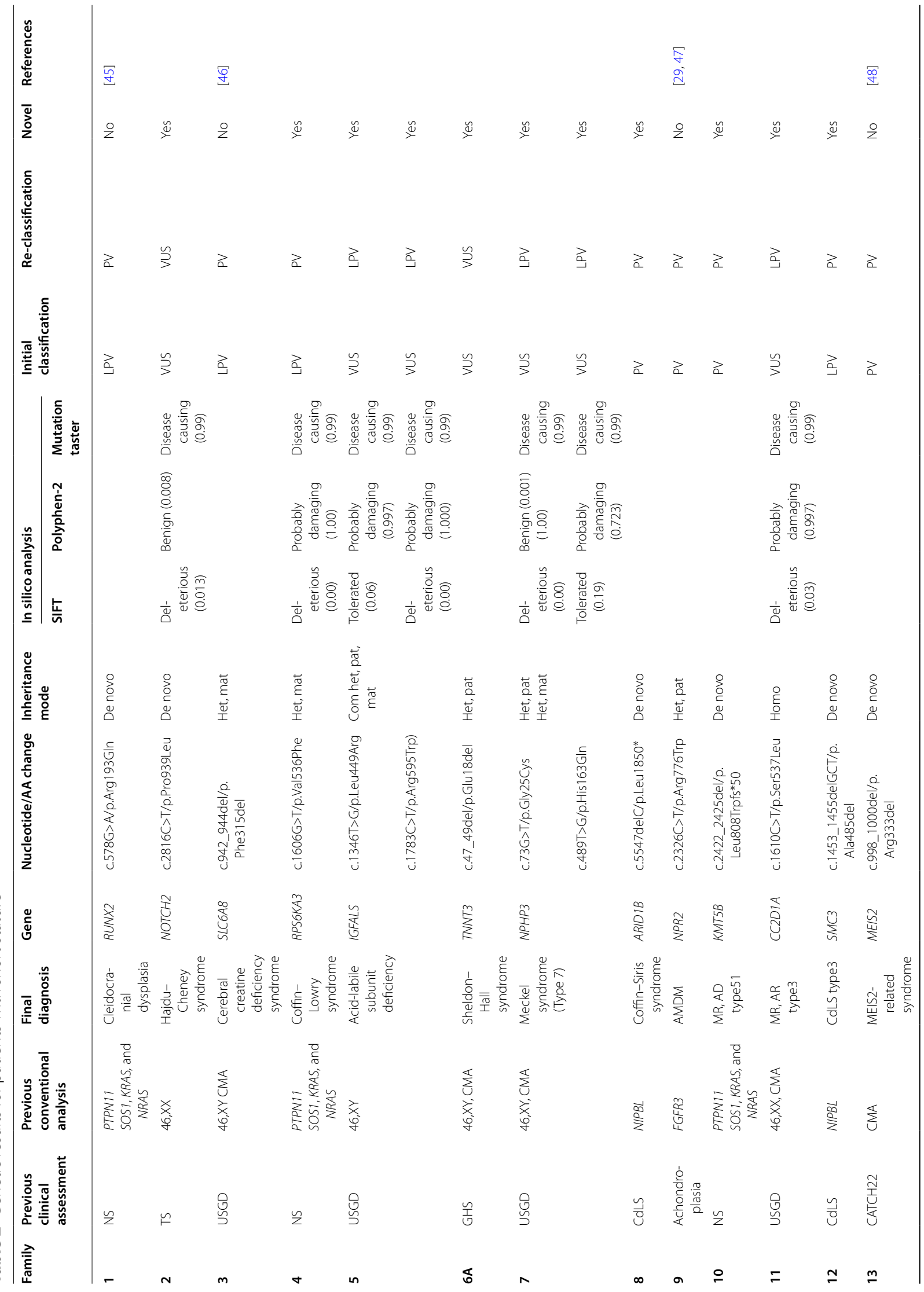




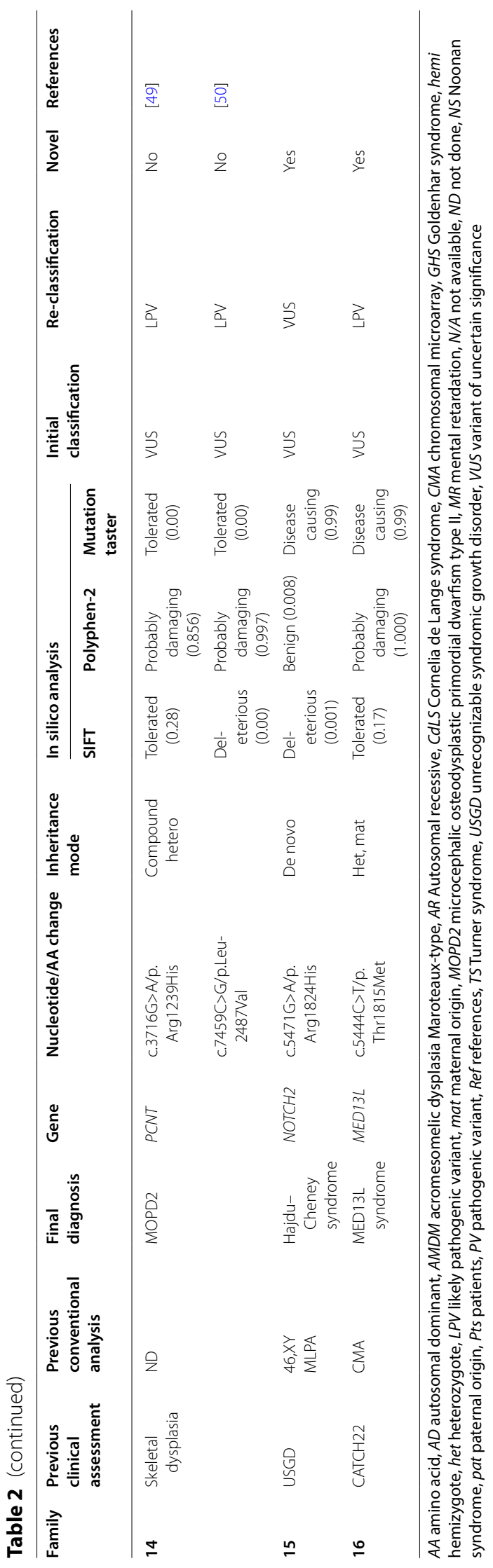


features, such as low set ears, short and broad digits, and cubitus valgus (Figs. 1a, 2a, b). Her skeletal survey revealed wormian bones in the lambdoidal suture, scoliosis, malocclusion, biconcave vertebra body, and coneshaped distal phalanges due to peripheral acro-osteolysis (Fig. 2c-f). Finally, she was diagnosed with HCS caused by a de novo missense variant, c.2816C $>\mathrm{T}$ (p.P939L) in the NOTCH2 gene (Fig. 2g).

Patient K6 was initially suspected of having Goldenhar syndrome based on clinical manifestations, such as asymmetric face, right cryptotia, nasolabial fold, and small mouth with a high arched roof of the mouth (Fig. 1d). He displayed camptodactyly and a congenital club foot. $\mathrm{He}$ had GHD with a delayed bone age. A novel small deletion, c.47_49del (p.E18del), in TNNT3 was identified in the proband and his family members and was responsible for Sheldon Hall syndrome (SHS).

Two (11.7\%) patients (K8 and K12) were initially suspected of having Cornelia de Lange syndrome based on dysmorphic facial features, such as synophrys and highly arched eyebrows, but mutations in NIPBL were not detected. Patient K8 was ultimately diagnosed with Coffin-Siris syndrome with a de novo novel variant, c.5547delC (p.L1850*), in ARID1B and patient K12 harbored a de novo novel variant, c.1453_1455delGCT (p.A485del), in SMC3, which is related to a mild variant of Cornelia de Lange syndrome with predominant ID.

Patient K9 was initially presumed to have achondroplasia during infancy; however, no mutation was found in FGFR3. Dysmorphic facial features, such as relatively macrocephaly with frontal bossing and micrognathia, were observed (Fig. 1f). Her height was $70 \mathrm{~cm}(-2.05$ SDS), with markedly short upper and lower extremities. Lower body X-rays demonstrated short tibia and fibula, with no missing or fused bones (Fig. 3a). Phalanges of the hands were short and broad with cone-shaped epiphyses, especially in the 4th proximal phalange (Fig. 3b). A missense mutation, c.2326C $>\mathrm{T}$ (p.A776W), in the kinase homology domain of the NPR2 gene was identified in the proband and her father (Fig. 3c).

Patient K14 displayed SS ( -2.8 SDS), genu varum, rhizomelia, and facial dysmorphism, including small chin, upward nostril, and low nasal bridge (Fig. 1g). His father was Korean and his mother was Japanese. Initially, he was suspected to have skeletal dysplasia. TES revealed a compound heterozygous mutation, c.3716G $>$ A (p.R1239H) and c.7459C $>\mathrm{G}$ (p.L2487V), in PCNT responsible for microcephalic osteodysplastic primordial dwarfism (MOPD) type II, inherited from his parents.

Two (11.7\%) patients (K13 and K16) were initially suspected to have $\mathrm{CATCH} 22$ syndrome based on facial features, but no microdeletion was detected by chromosomal microarray. Patient K13 displayed severe SS
(-4.10 SDS), dysmorphic facial features, such as low set ears, cleft palate, and congenital heart defect. A de novo small deletion (c.998_1000del) in MEIS2 responsible for MEIS2-related syndrome was detected. Patient K16 presented with proportionate SS $(-6.10$ SDS) and ID. She had facial dymorphism, such as fished mouth and hypertelorism (Fig. 1j), congenital heart disease, and hydrocephalus. Her mother and two siblings also had ID and similar dysmorphic facial features, such as a fish-mouth appearance, flat nasal bridge with bulbous nasal tip, hypertelorism, and triangular face. A novel missense mutation, c.5444C>T (p.T1815M), in MED13L associated with MED13L syndrome was identified in the proband and her siblings, and this mutation was inherited from her mother (Fig. 4a).

The comparison of clinical features between genetically positive cases and negative cases are depicted in Additional file 1. The frequency of the dysmorphic face was statistically higher in the positive cases compared to the negative cases $(94.1 \%$ vs. $52.9 \%, p=0.017$, odds ratio 13.15).

\section{Diagnostic yield, classification, and characteristics of variants}

Among 34 patients with suspected syndromic SS, genetic diseases were identified in 17 patients (50\%) when PV, LPV, and VUS are included. However, when only PV and LPV excluding VUS are included, the diagnosis rate was $38.2 \%$. Sixteen (94.1\%) underwent a genetic and/or cytological analysis prior to TES. These patients were assessed by Sanger sequencing as well as family member testing and segregation analyses, yielding 19 variants, including 13 (68.4\%) novel variants responsible for 15 genetic disorders (Table 2). Nine novel missense variants were predicted to be deleterious by at least one of three bioinformatics algorithms (i.e., SIFT, PolyPhen2, and MutationTaster). With respect to the mode of inheritance, $40 \%$ cases were autosomal dominant de novo (6/15), 26.7\% were autosomal recessive (4/15), 13.3\% were X-linked (2/15), and $13.3 \%$ were autosomal dominant with unknown inheritance $(2 / 15)$. Looking at the distribution of causative variants, pathogenic variants accounted for $21.1 \%(4 / 19)$, likely pathogenic variants accounted for $21.1 \%(4 / 19)$, and VUS accounted for $57.9 \%$ (11/19) (Table 2). However, after re-classification by clinical reassessment, such as family member testing and segregation studies, pathogenic variants accounted for $42.1 \%$ (8/19), likely pathogenic variants $42.1 \%(8 / 19)$, and VUS $15.7 \%(3 / 19)$ (Table 2). For confirmed causative variants, missense was the most common type, with a frequency of $68.4 \%(13 / 19)$, followed by frame-in/del with a frequency of $26.3 \%(5 / 19)$ and frameshift with a frequency of $5.3 \%$ 

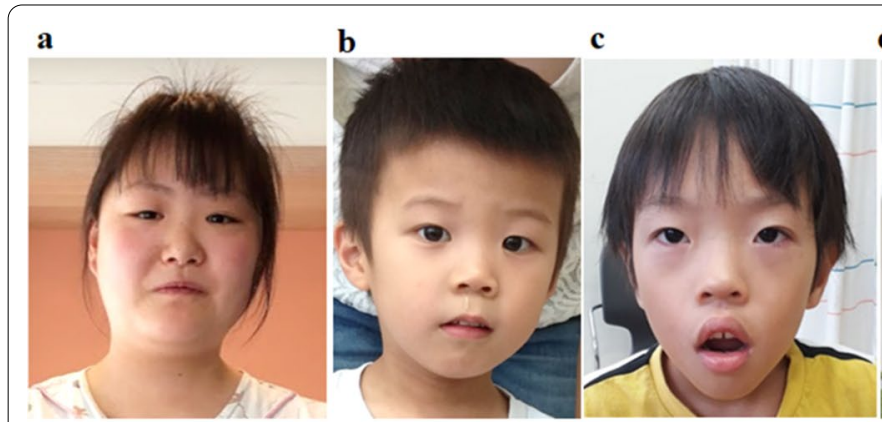

d

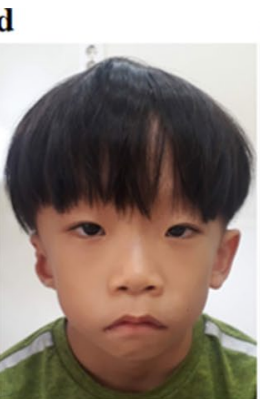

g

h

i

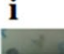

j

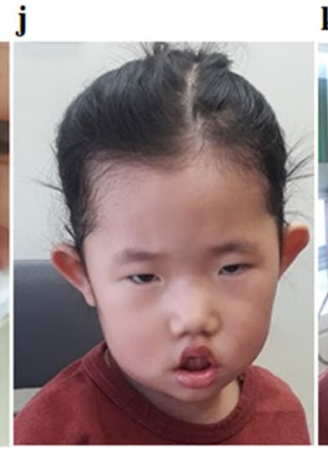

e

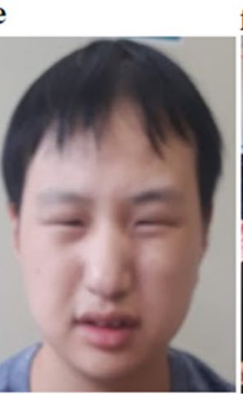

k f

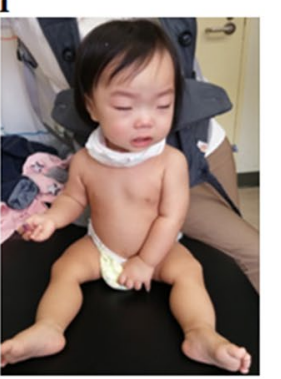

l
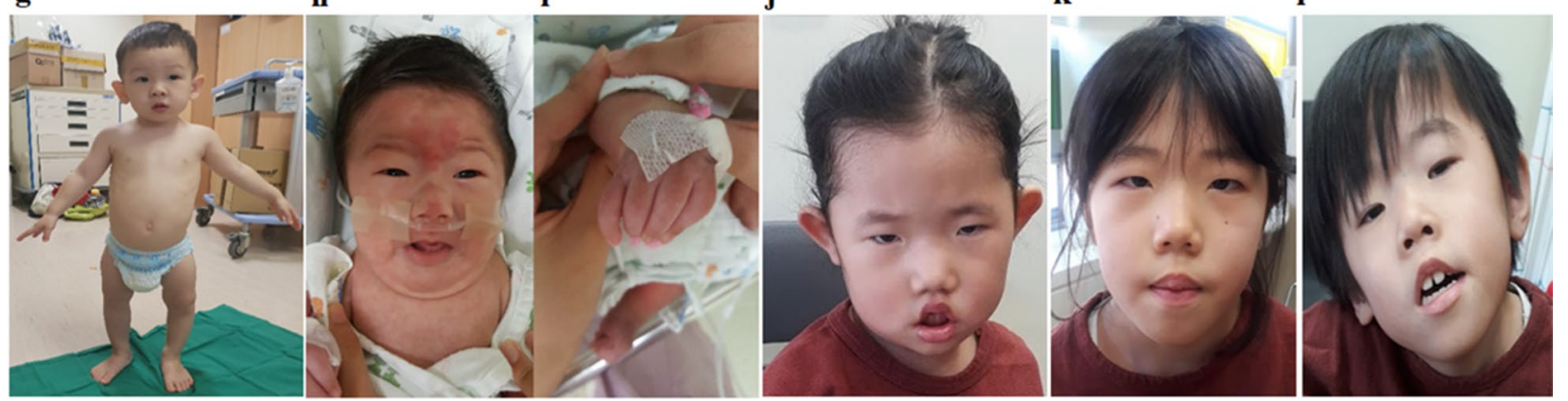

Fig. 1 Characteristic features of the face and body in individuals with short stature. a Hypertelorism, small mouth, and low-set ears, in patient K2 with Hajdu-Cheney syndrome; b subtle dysmorphic facial features, such as long face, in patient K3 with cerebral creatinine deficiency; $\mathbf{c}$ hypertelorism, epicanthal fold, broad nose, anteverted nares, short philtrum, large mouth, thick/everted lips, and large ears, in patient K4 with Coffin-Lowry syndrome; $\mathbf{d}$ triangular face, upward slanting palpebral fissures, right cryptotia, nasolabial folds, small mouth with a high, arched roof of the mouth, and webbed neck in patient K6 with Sheldon-Hall syndrome; e microcephaly, prominent and narrow nose, short philtrum, and micrognathia in patient K7 with Meckel syndrome (Type 7); $\mathbf{f}$ relative macrocephaly with frontal bossing, short arms and legs, and brachydactyly in patient K9 with acromesomelic dysplasia Maroteaux-type; $\mathbf{g}$ small chin, upward nostril, and low nasal bridge, rhizomelia, and genu varum in patient K14 with microcephalic osteodysplastic primordial dwarfism type I; $\mathbf{h}$, i coarse face, long philtrum, and hand deformity in patient K15 with HajduCheney syndrome; $\mathbf{j}$ hypotonic fish-mouth appearance, hypertelorism, and flat nasal bridge with bulbous nasal tip in patient K16 with MED13L syndrome; $\mathbf{k}$, I her (patient K16) siblings with the same mutation in MED13L

(1/19). Ultra-rare diseases accounted for 12 out of 15 genetic diseases (80\%) (Fig. 5).

\section{Identification of ultra-rare genetic diseases and its impact on clinical management}

The confirmation of an ultra-rare genetic disease by TES affected patient management. Disease monitoring was initiated in $52.9 \%$ of patients. In addition, the systemic involvement of specific genetic diseases was investigated in $41.1 \%$ of patients, the estimated inheritance pattern was changed in $11.7 \%$, and prognosis was changed in $11.7 \%$. Medical interventions were initiated in $5.8 \%$ of patients, and reproductive planning was initiated in $5.8 \%$ of patients. For example, patient K3 displayed a speech delay, suspected autism spectrum disorder, and SS. He had only been receiving speech rehabilitation treatment for unknown speech delays. CMA and karyotyping analyses showed negative results. After TES, a hemizygous small deletion, c.942_944 (p.F315del), in SLC6A8, responsible for
X-linked cerebral creatine deficiency, was detected in both the patient and his mother (Fig. 6a, b). His mother's cousin's son also showed speech delays and SS. Baseline MR spectroscopy showed a decreased creatine peak level of $2.42 \mathrm{ppm}$ in both the parietal and right temporal lobes (Fig. 6c), and a urine analysis revealed a significant elevation in the creatine/creatinine ratio (43.9, ref; 0.017-0.720) corresponding to a creatine transporter deficiency. After the final diagnosis, the patient was administered oral arginine $(400 \mathrm{mg} / \mathrm{kg} /$ day), glycine $(150 \mathrm{mg} / \mathrm{kg} /$ day $)$, and creatine $(400 \mathrm{mg} /$ $\mathrm{kg} /$ day). We observed progressive improvements in developmental skills, such as the Sequenced Language Scale for Infants (from $<1 \%$ percentile to $3 \%$ percentile), K-Vineland-II (SQ from 37 to 40, K-CARS-ST (from 38.5 to 35), and K-CARS-2 (from 100 to 65), as well as an increased creatine peak of $9.11 \mathrm{ppm}$ in both the parietal and right temporal lobes by MR spectroscopy (Fig. 6d) and a decreased creatine/creatinine ratio (43.9, ref; $0.017-0.720$ ) after 2.5 years of oral supplementation. 


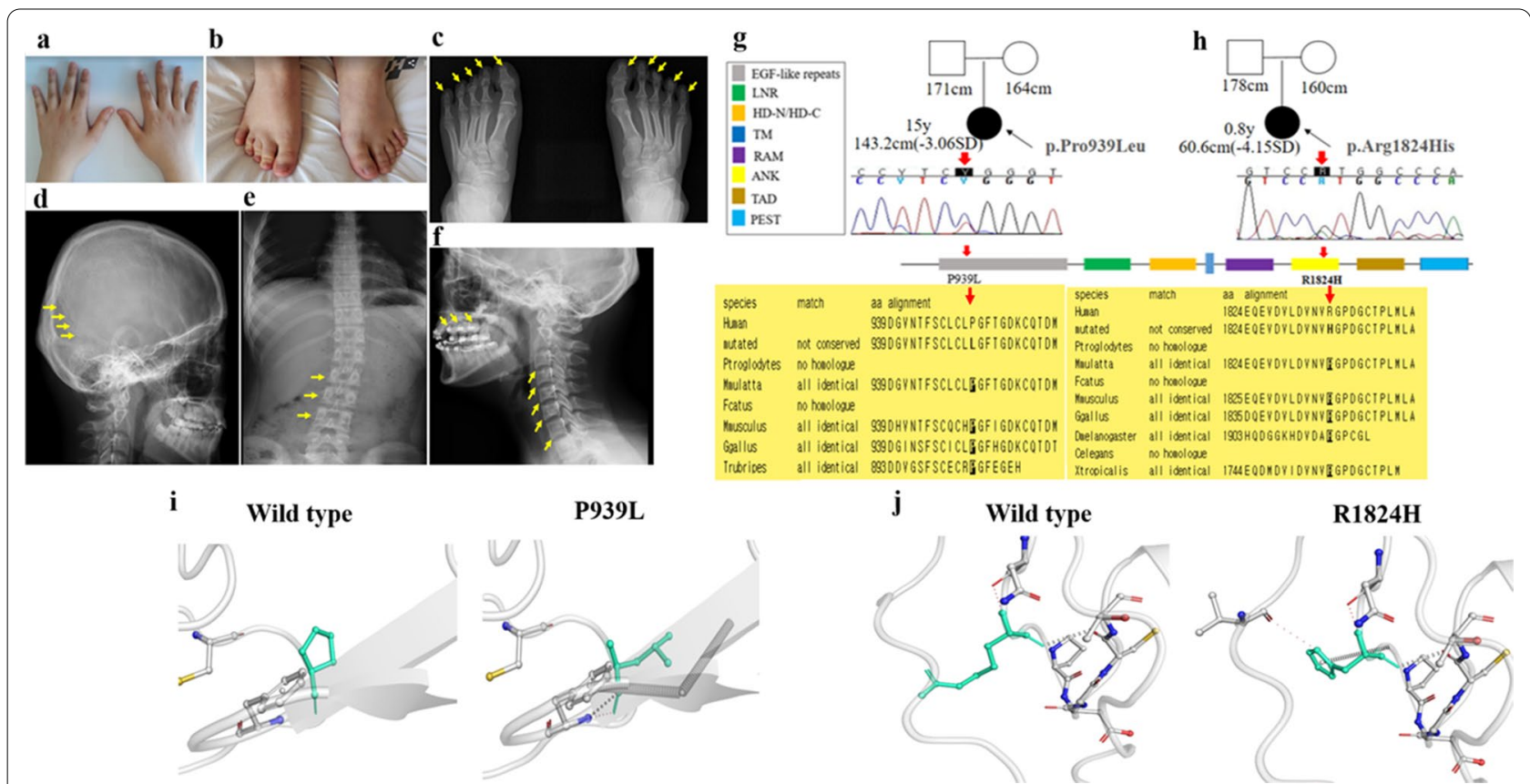

Fig. 2 Visual findings, radiographic skeletal survey, and genetic analysis in patient K2 with Hajdu-Cheney syndrome. a, b Short and broad digits were observed; c cone-shaped distal phalanges due to peripheral acrolysis is indicated by yellow arrows; $\mathbf{d}$ wormian bones are marked by yellow arrows in the lambdoidal suture; e lumbar scoliosis is marked by yellow arrows; $\mathbf{f}$ malocclusion and biconcave vertebra bodies marked by yellow arrows. Two novel heterozygous variants in the NOTCH2 gene (NM_024408.3). g, h S Sanger sequencing confirmed two de novo novel variants, c.2816C>T (p.P939L) and c.5471G>A (p.R1824H), in NOTCH2 in patients K2 and K15, respectively, shown by the red arrow. P939 located on EGF-like repeats and $\mathrm{R} 1824 \mathrm{H}$ on ankyrin repeat domain residues are conserved among species, shown in the dark square box. Sequences were aligned using blastp [https://blast.ncbi.nlm.nih.gov/]; i, j wild-type and mutant residues (p.P939L and p.R1824H) in the NOTCH2 protein are shown in light-green and are also represented as sticks alongside the surrounding residues, indicating any type of interaction. Purple dots represent metal complex interactions with a surrounding residue. Orange dots represent weak hydrogen bonds with a surrounding residue. The crystal structure of the domain from wild-type NOTCH2 was generated by SWISS-MODEL [https://swissmodel.expasy.org/] and depicted as a cartoon representation. All structural images were generated using PyMOL (https://pymol.org/)

\section{Discussion}

In a study of 34 patients with clinically suspected syndromic SS, we identified 19 genetic variants in 17 (50\%) patients, including 13 (68.4\%) novel variants responsible for 15 rare genetic disorders.

Originally, in 6 of 17 patients (35.2\%), the cause of SS was generally considered to be GHD or SGA and was finally identified as an underlying genetic disease by TES. In clinical practice, in-depth TES analyses can reveal various genetic diseases related to SS, including ultra-rare diseases, emphasizing the importance of this approach in pediatric endocrinology. A cohort study of Chinese children with SS showed a high diagnostic yield of 33.3\% through TES/WES comparing to that of chromosomal microarray analysis (1.8\%) [15]. Similarly, a previous smaller study of 14 highly selected patients with SS reported a diagnostic yield of 36\% through WES [16]. However, Hauer et al. reported a slightly lower diagnosis rate of $16 \%$ through WES to identify the underlying cause of SS [17]. On the other hand, Freire et al. reported a diagnostic yield of $15 \%$ through target panel and exome sequencing [18]. The diagnostic yield might be affected by the study's strict inclusion criteria, test methods, and sample size.

In this study, if we look closely at the rare monogenic causes of SS identified through TES, two patients (11.7\%) were diagnosed with HCS, a rare connective tissue disease characterized by acroosteolysis of the hands and feet, developmental defects of bones and joints causing distinctive craniofacial and skull changes, as well as severe osteoporosis and SS [19]. The craniofacial developmental abnormalities are probably related to the effects of Notch on skeletal development, and the SS may be secondary to the inhibitory effects of Notch on chondrogenesis [19]. Based on the limited number of HCS cases reported to date, the common pathogenic mechanism seems to involve nonsense mutations or deletions, leading to a termination codon in exon 34 of NOTCH2 upstream of the PEST domain [20-22]. Interestingly, two de novo novel variants, P939L and $\mathrm{R} 1824 \mathrm{H}$, in two cases (K2 and K15) in the present study were located in the calcium-binding EGF-like domain and Ankyrin 2 domain, 


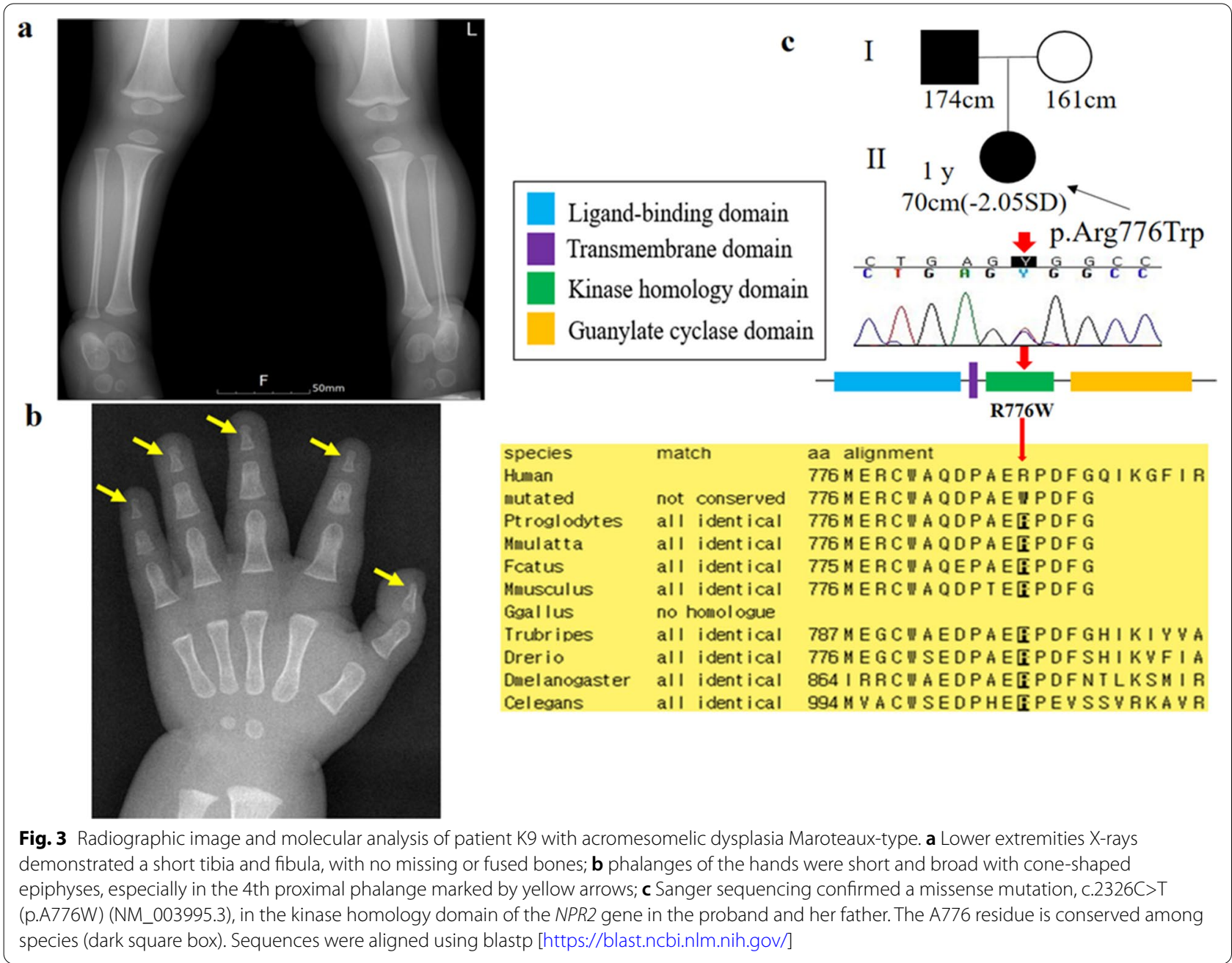

respectively (Fig. 2g, h), which has not been reported previously. The allele frequencies of these two variants in East Asia were 0.001403 and 0.000000 , respectively. Protein crystal structures revealed that the P939L variant might affect the metal complex interactions with surrounding residues (Fig. 2i), while the $\mathrm{R} 1824 \mathrm{H}$ variant affected weak hydrogen bonds and metal complex interactions (Fig. 2j).

Rare skeletal disorders leading to severe SS and abnormal skeletal morphologies often have genetic etiologies in children. In this study, rare genetic skeletal disorders were identified by TES. First, SHS (MIM\# 601680) or distal arthrogryposis type $2 \mathrm{~B}$ is an autosomal dominant disorder characterized by congenital contractures of the distal joints of the limbs without a primary neurological defect [11]. The most common clinical features of SHS include a triangular face, prominent nasolabial folds, small mouth, high arched palate, attached earlobes, mild cervical webbing, SS, severe camptodactyly, ulnar deviation, and vertical talus and/or talipes equinovarus [11].
In the present study, the first Korean family with a novel variant in TNNT3 associated with SHS was identified in patient K6. Although SHS is a rare disease, it can exhibit autosomal dominance, and familial recurrence has been reported in approximately $50 \%$ of cases [13]. Our patient had metatarsus varus at a young age. His grandmother, father, uncle, and elder brother were all short. Interestingly, while his intelligence was normal, his uncle and brother showed a mild ID, suggesting phenotypic variability. Recently, mutations in genes encoding the skeletal muscle contractile fiber complex (TNNI2, TNNT3, TPM2, MYH3, and MYBPC1) have been identified as causes of distal arthrogryposis types 1 and 2 [23]. MYH3 mutations account for $32 \%$ of SHS cases [24]. In Korea, only patients with mutations in TPM2 related to SHS have been reported previously [25]. For SHS with genetic heterogeneity corresponding to phenotypic variation, TES can be a very useful diagnostic tool.

Second, acromesomelic dysplasia Maroteaux-type (AMDM) was detected in patient K9 with heterozygous 

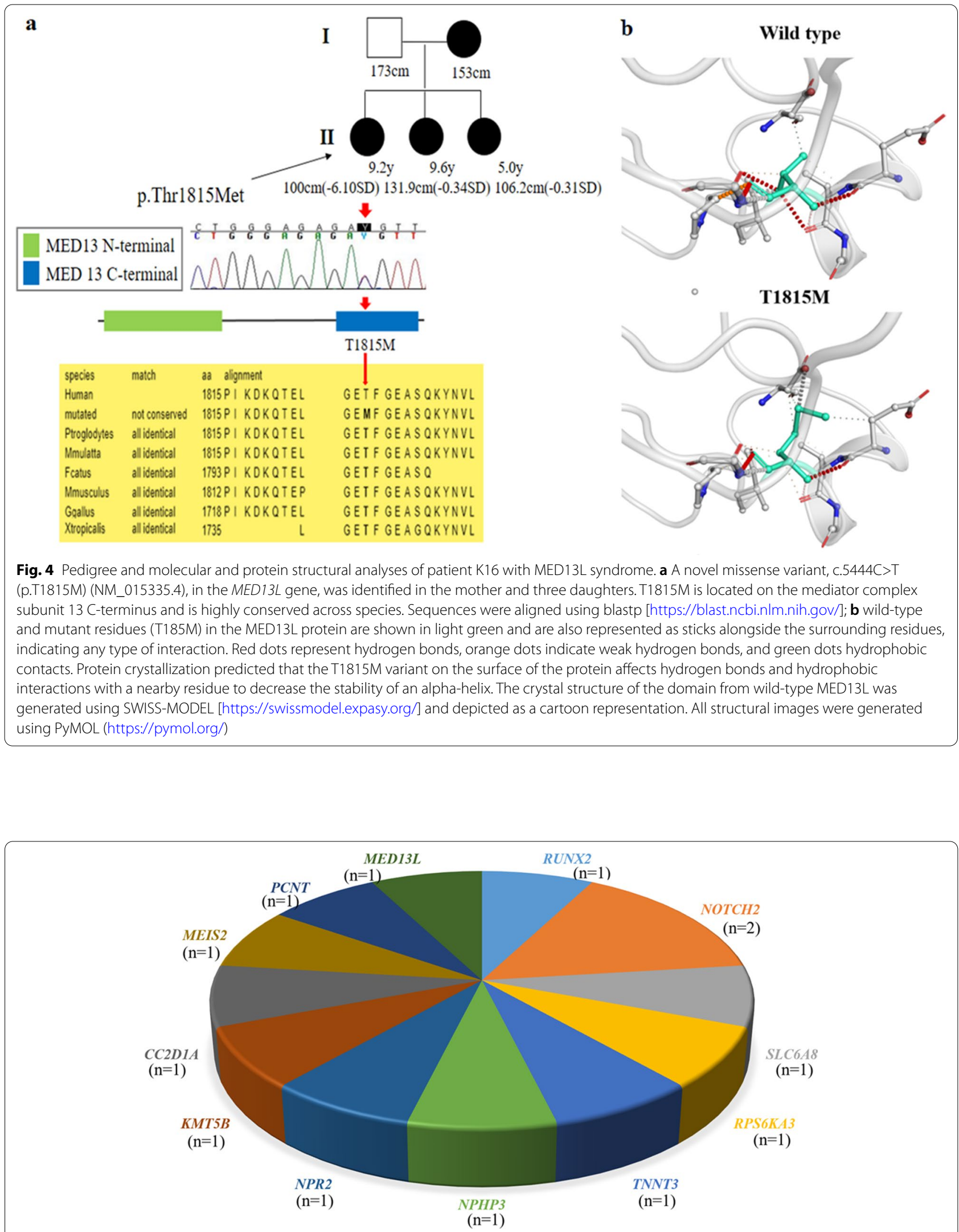

Fig. 5 Mutated genes related to ultra-rare diseases identified in the study 


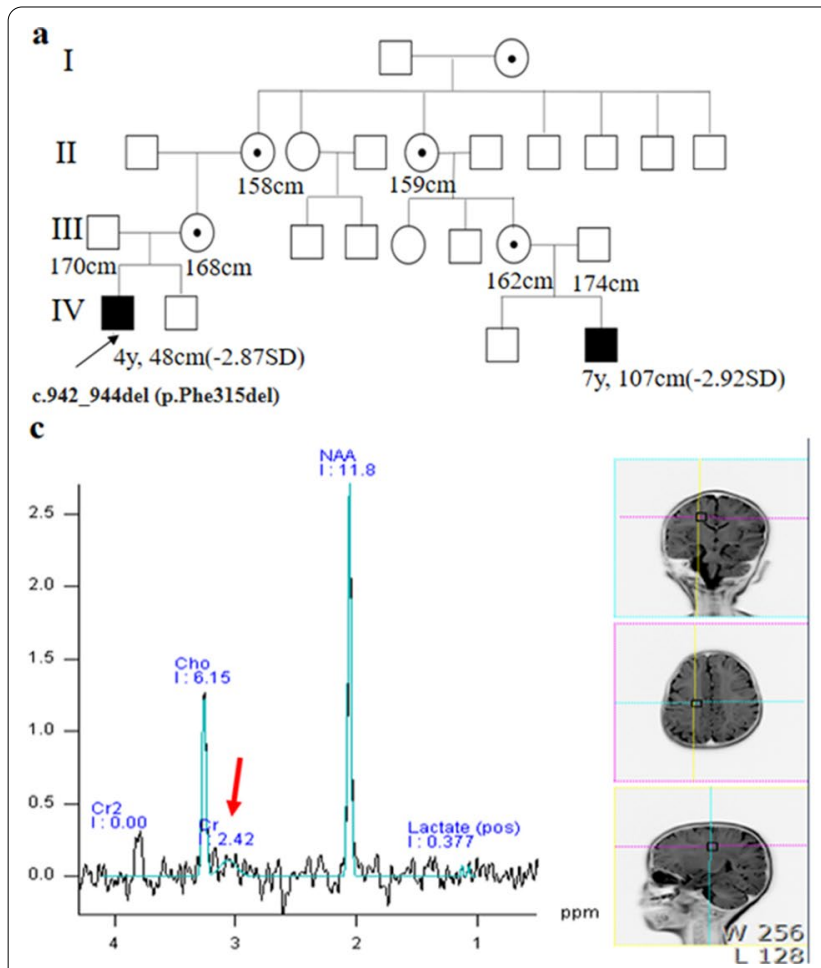

b
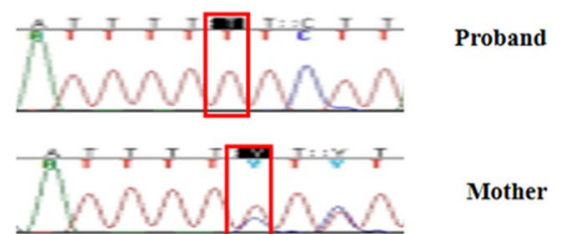

d

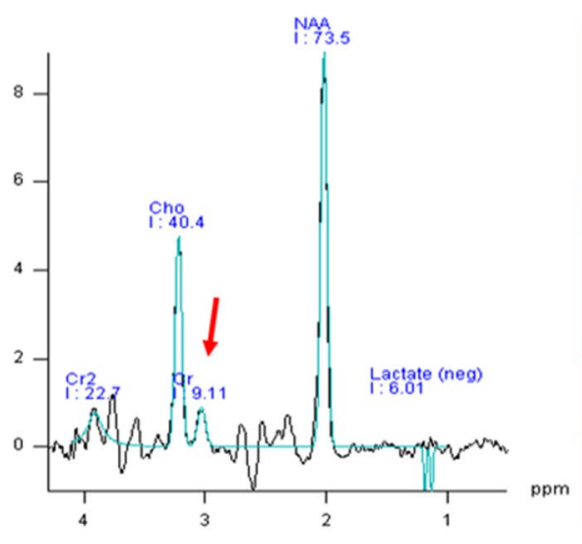

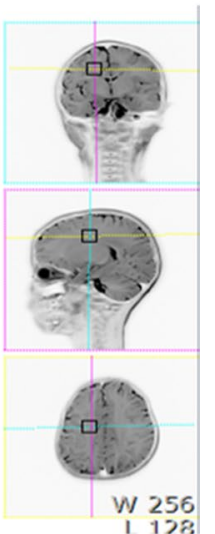

Fig. 6 Pedigree and molecular analysis and brain image work-up for patient K3 with creatinine cerebral deficiency. a A pedigree analysis shows that the genetic disease in the family of patient 2 is inherited in an X-linked recessive manner; $\mathbf{b}$ Sanger sequencing confirmed a hemizygous in-frame deletion variant, c.942_944del (p.F315del) (NM_005629.3), in SLC6A8 identified by targeted exome sequencing, shown in the red rectangular box; c MR spectroscopy reveals a diminished creatine signal peak, indicated by thick red arrows in both the parietal lobe and right temporal lobe at baseline. Concentration of $\mathrm{N}$-acetyl aspartate (NAA) and cholines (Cho) were within normal ranges; $\mathbf{d}$ MR spectroscopy demonstrates an elevated creatine signal peak indicated by the thick red arrow in both the parietal lobe and right temporal lobe after 2.5 years of oral treatment with creatine, arginine, and glycine supplementation

missense mutation, R776W, in NPR2. AMDM is a rare autosomal recessive skeletal disorder that leads to severe SS and an abnormal skeletal morphology [26]. The height of her father, who was a carrier with AMDM, was normal $(174 \mathrm{~cm})$, and he had the normal shape and proportion of the skeletal elements. Individuals with classic AMDM have severe SS with significant shortening of the middle and distal parts of their limbs, especially the hands and feet [27]. Interestingly, carriers with AMDM often have SS and mild skeletal defects; however, height in NPR2 heterozygotes is highly variable, ranging from short to normal [26, 28]. The R776W mutation located within the kinase homology domain was originally reported in a Turkish family, and carriers of this mutation are shorter than matched controls [29]. The kinase homology domain binds to ATP and contributes to the regulation of guanylyl cyclase activity and bone growth in response to C-type natriuretic peptide [30]. Bartels et al. found that the average height of 30 adult carriers of AMDM was $5.7 \mathrm{~cm}$ shorter than that of population-matched controls [29]. Recently, Hwang et al. identified heterozygous NPR2 mutations in $2.6 \%$ of Korean subjects with idiopathic SS, and these mutations have a dominant-negative effect on growth signals based on in vitro functional analyses [31].

Third, MOPD type II was identified in patient K14; this condition is characterized by the disproportionate shortening of the fore-arms and legs, short stature with other skeletal abnormalities (osteodysplasia), microcephaly, and a phenotype consistent with Seckel syndrome [32]. Other skeletal abnormalities include abnormal development of the hip joints (hip dysplasia), cox vara, thinning of the bones in the arms and legs, and shortened wrist bones [32]. Our patient also displayed cox vara, genu varum, and both slipped capital femoral epiphysis, compatible with MOPD type II (Additional file 2). The pericentrin gene (PCNT) [OMIM \#605925] encodes a large coiled-coil protein that localizes to the pericentriolar material, where it interacts with several structural centrosomal proteins, including $\gamma$-tubulin and PCM1, involved in centrosome function and spindle assembly [33]. The perturbation of cell division not only affects brain size but also body size [34]. Of interest, most pathogenic mutations previously reported in patients with MOPD type II are 
truncation mutations [34, 35], whereas our patient had two missense mutations, c.3716G $>\mathrm{A}(\mathrm{R} 1239 \mathrm{H})$ and c.7459C > G (L2487V), in PCNT. The $\mathrm{R} 1239 \mathrm{H}$ variant was located on the structural maintenance of chromosomes (SMC) protein domain, while L2487V is expected to interact with NEK2, which plays a key role in the regulation of mitotic processes.

In addition to the skeletal disorders causing SS, we observed a rare genetic syndrome, MED13L, which involves abnormalities in both early heart and brain development [36]. Individuals with MED13L syndrome develop postnatal SS [37]. The common facial gestalt shows some resemblance to that of 22q11.2 microdeletion syndrome [38]. The majority of reported mutations are de novo, and missense mutations remain VUS [32]. Patient K16 was the first Korean familial case with a novel missense variant, c.5444C $>\mathrm{T}$ (p.T1815M), in MED13L, which is maternally inherited. This variant was not found in the ExAC or 1000 Genomes databases. T1815M is located on the mediator complex subunit $13 \mathrm{C}$-terminus and is highly conserved across species (Fig. 4a). Protein crystal structures predicted that the T1815M variant located on the surface affects hydrogen bonds and hydrophobic interactions with a nearby residue to decrease the stability of an alpha-helix, thereby affecting the MED13L secondary structure (Fig. 4b). MED13L, a protein with an uncharacterized structure, is a subunit of the mediator complex that links DNA-binding transcription factors and RNA polymerase II for gene transcription [39]. The mediator is an evolutionarily conserved multi-protein complex with diverse and dynamic roles at multiple stages of transcription [40]. To date, 26 patients with likely truncating/loss-of-function de novo aberrations of $M E D 13 L$ have been reported, all showing ID/DD and a spectrum of facial anomalies [38]. Notably, the older sister and younger sister of the patient carried the same mutation, and both had similar facial appearances and ID without SS ( -0.34 SDS and -0.31 SDS, respectively). The mother showed similar facial appearances to those of her daughters but showed a normal height ( -1.25 SDS) and intellectual functions. The phenotype variability in a Korean family with MED13L syndrome may be associated with a novel $M E D 13 L$ variant.

Finally, as a result of comparing the clinical characteristics such as height SDS, facial dysmorphism, visual involvement, intellectual disability or developmental delay, microcephaly, skeletal deformities, congenital heart disease, and renal anomalies of the genetically positive group and the negative group, the frequency of facial dysmorphism was higher in the genetically positive group than in the genetically negative group. Therefore, if the child short stature and facial dysmorphism is accompanied, it is expected that the possibility of identifying the underlying etiology of short stature may be high when the genetic evaluation using TES is performed.

However, this study has diagnostic limitations. Of the 19 alleles found in 17 patients, 3 (15.7\%) were identified as VUS, limiting their diagnostic value. Therefore, it will be necessary for the future to verify the pathogenicity of variants by various algorithmic-based methods and functional studies to improve the robust diagnosis rate. In addition, no pathogenic variants were found in the remaining 17 patients. It is required to perform a further genetic work-up through long-read trio sequencing among individuals with unsolved cases. Because short-read sequencing methods often lack sensitivity and specificity for a large proportion of structural variants (SV) due to technical limitations [41, 42]. Each human genome harbors thousands of SV, in total spanning more than $10 \mathrm{Mb}$, that have largely remained undetected with conventional short-read sequencing [41-44]. These limitations can be overcome by longread sequencing.

In conclusion, a positive result $(50.0 \%)$ from genetic testing was high in patients with suspected syndromic SS, including the identification of 13 novel heterozygous variants by TES. These results support the use of TES as a promising tool for uncovering the causes of syndromic SS and broadly contribute to our understanding of the etiology and clinical features of SS in Korea.

\section{Abbreviations}

TES: Targeted exome sequencing; WES: Whole exome sequencing; CMA: Chromosomal microarray; SS: Short stature; MPH: Mid-parental height; SDS: Standard deviation score; IGF-1: Insulin-like growth factor 1; IGFBP-3: Insulinlike growth factor-binding protein 3; HCS: Hajdu-Cheney syndrome; GHD: Growth hormone deficiency; MOPD: Microcephalic osteodysplastic primordial dwarfism; SHS: Sheldon Hall syndrome; AMDM: Acromesomelic dysplasia Maroteaux-type; VUS: Variant of uncertain significance.

\section{Supplementary Information}

The online version contains supplementary material available at https://doi. org/10.1186/s13023-021-01937-8.

Additional file 1. Supplementary 1. Comparison of clinical features between genetically positive cases and negative cases.

Additional file 2. Radiographic image of patient K14 with microcephalic osteodysplastic primordial dwarfism (MOPD) type II. X-ray findings show coxa vara, genu varum, and both slipped capital femoral epiphysis marked by yellow arrows.

\section{Acknowledgements}

We gratefully acknowledge the cooperation of the patients and their families. Finally, we would like to thank Editage (www.editage.co.kr) for English language editing.

Authors' contributions

GK and CKC involved in data acquisition, data analysis, drafting the manuscript. JYY and SDY revised the manuscript. CKC involved in patient 
recruitment and management. All authors read and approved the final manuscript.

\section{Funding}

This study was supported by a 2021 research grant from Pusan National University Yangsan Hospital.

\section{Availability of data and materials}

The datasets used and/or analyzed during the current study are available from the corresponding author on reasonable request.

\section{Declarations}

\section{Ethics approval and consent to participate}

This study has been approved by the Institutional Review Board of Pusan National University Yangsan Hospital (IRB Ref. Nos.: L-2020-243). Written informed consent for the study was obtained from all study participants.

\section{Consent for publication}

Consent was obtained from all patients for publication.

\section{Competing interests}

Gilyazetdinov Kamil, Ju Young Yoon, Sukdong Yoo, Chong Kun Cheon G report no conflict of interest.

\section{Author details}

${ }^{1}$ Department of Pediatrics, National Children's Medical Center, Tashkent, Uzbekistan. ${ }^{2}$ Division of Pediatric Endocrinology, Department of Pediatrics, Pusan National University Children's Hospital, Yangsan, Korea. ${ }^{3}$ Research Institute for Convergence of Biomedical Science and Technology, Pusan National University Yangsan Hospital, Yangsan, Korea.

Received: 16 February 2021 Accepted: 27 June 2021

Published online: 03 July 2021

\section{References}

1. Haymond M, Kappelgaard AM, Czernichow P, Biller BM, Takano K, Kiess W, et al. Early recognition of growth abnormalities permitting early intervention. Acta Paediatr. 2013;102(8):787-96.

2. Dauber A, Rosenfeld RG, Hirschhorn JN. Genetic evaluation of short stature. J Clin Endocrinol Metab. 2014;99(9):3080-92.

3. Wood AR, Esko T, Yang J, Vedantam S, Pers TH, Gustafsson S, et al. Defining the role of common variation in the genomic and biological architecture of adult human height. Nat Genet. 2014:46:1173-86.

4. Marouli E, Graff M, Medina-Gomez C, Lo KS, Wood AR, Kjaer TR, et al. Rare and low-frequency coding variants alter human adult height. Nature. 2017;542:186-90.

5. Speed D, Hemani G, Johnson MR, Balding DJ. Improved heritability estimation from genome-wide SNPs. Am J Hum Genet. 2012;91(6):1011-21.

6. Agarwala V, Flannick J, Sunyaev S, GoT2D Consortium, Altshuler D. Evaluating empirical bounds on complex disease genetic architecture. Nat Genet. 2013;45(12):1418-27.

7. Chernausek SD, Backeljauw PF, Frane J, Kuntze J, Underwood LE. Longterm treatment with recombinant insulin-like growth factor (IGF)-I in children with severe IGF-I deficiency due to growth hormone insensitivity. J Clin Endocrinol Metab. 2007;92(3):902-10.

8. Polidori N, Castorani V, Mohn A, Chiarelli F. Deciphering short stature in children. Ann Pediatr Endocrinol Metab. 2020;25(2):69-79.

9. Bras J, Guerreiro R, Hardy J. Use of next-generation sequencing and other whole-genome strategies to dissect neurological disease. J Nat Rev Neurosci. 2012;13(7):453-64.

10. Guo MH, Shen Y, Walvoord EC, Miller TC, Moon JE, Hirschhorn JN, et al. Whole exome sequencing to identify genetic causes of short stature. Horm Res Paediatr. 2014;82(1):44-52.

11. Toydemir RM, Bamshad MJ. Sheldon-Hall syndrome. Orphanet J Rare Dis. 2009:4:11

12. Wang SR, Carmichael H, Andrew SF, Miller TC, Moon JE, Derr MA, et al. Large-scale pooled next-generation sequencing of 1077 genes to identify genetic causes of short stature. J Clin Endocrinol Metab. 2013;98(8):E1428-37.

13. Sung SS, Brassington AM, Krakowiak PA, Carey JC, Jorde LB, Bamshad M. Mutations in TNNT3 cause multiple congenital contractures: a second locus for distal arthrogryposis type 2B. Am J Hum Genet. 2003;73:212-4.

14. Hennekam RC. Care for patients with ultra-rare disorders. Eur J Med Genet. 2011;54(3):220-4.

15. Huang Z, Sun Y, Fan Y, Wang L, Liu H, Gong Z, et al. Genetic evaluation of 114 Chinese Short Stature Children in the next generation era: a single center study. Cell Physiol Biochem. 2018;49(1):295-305.

16. Kim YM, Lee YJ, Park JH, Lee HD, Cheon CK, Kim SY, et al. High diagnostic yield of clinically unidentifiable syndromic growth disorders by targeted exome sequencing. Clin Genet. 2017;92(6):594-605.

17. Hauer NN, Popp B, Schoeller E, Schuhmann S, Heath KE, Hisado-Oliva A, et al. Clinical relevance of systematic phenotyping and exome sequencing in patients with short stature. Genet Med. 2018;20(6):630-8.

18. Freire BL, Homma TK, Funari MFA, Lerario AM, Vasques GA, Malaquias $A C$, et al. Multigene sequencing analysis of children born small for gestational age with isolated short stature. J Clin Endocrinol Metab. 2019:104(6):2023-30

19. Canalis E, Zanotti S. Hajdu-Cheney syndrome: a review. Orphanet J Rare Dis. 2014;9:200.

20. Isidor B, Lindenbaum P, Pichon O, Bézieau S, Dina C, Jacquemont S, et al. Truncating mutations in the last exon of $\mathrm{NOTCH} 2$ cause a rare skeletal disorder with osteoporosis. Nat Genet. 2011;43(4):306-8.

21. Majewski J, Schwartzentruber JA, Caqueret A, Patry L, Marcadier J, Fryns JP, et al. Mutations in NOTCH2 in families with Hajdu-Cheney syndrome. Hum Mutat. 2011;32:1114-7.

22. Zhao W, Petit E, Gafni Rl, Collins MT, Robey PG, Seton M, et al. Mutations in NOTCH2 in patients with Hajdu-Cheney syndrome. Osteoporos Int. 2013:24:2275-81.

23. Zhao N, Jiang M, Han W, Bian C, Li X, Huang F, et al. A novel mutation in TNNT3 associated with Sheldon-Hall syndrome in a Chinese family with vertical talus. Eur J Med Genet. 2011;54:351-3.

24. Toydemir RM, Rutherford A, Whitby FG, Jorde LB, Carey JC, Bamshad MJ. Mutations in embryonic myosin heavy chain (MYH3) cause Freeman-Sheldon syndrome and Sheldon-Hall syndrome. Nat Genet. 2006;38:561-5.

25. Ko JM, Choi IH, Baek GH, Kim KW. First Korean family with a mutation in TPM2 associated with Sheldon-Hall syndrome. J Korean Med Sci. 2013;28:780-3.

26. Hisado-Oliva A, Garre-Vázquez Al, Santaolalla-Caballero F, Belinchón A, Barreda-Bonis AC, Vasques GA, et al. Heterozygous NPR2 mutations cause disproportionate short stature, similar to Léri-Weill dyschondrosteosis. J Clin Endocrinol Metab. 2015;100(8):E1133-42.

27. Faivre L, Le Merrer M, Megarbane A, Gilbert B, Mortier G, Cusin V, et al. Exclusion of chromosome 9 helps to identify mild variants of acromesomelic dysplasia Maroteaux type. J Med Genet. 2000;37:52-4.

28. Vasques GA, Amano N, Docko AJ, Funari MF, Quedas EP, Nishi MY, et al. Heterozygous mutations in natriuretic peptide receptor-B (NPR2) gene as a cause of short stature in patients initially classified as idiopathic short stature. J Clin Endocrinol Metab. 2013;98(10):E1636-44.

29. Bartels CF, Bükülmez H, Padayatti $P$, Rhee DK, van Ravenswaaij-Arts C, Pauli RM, et al. Mutations in the transmembrane natriuretic peptide receptor NPR-B impair skeletal growth and cause acromesomelic dysplasia, type Maroteaux. Am J Hum Genet. 2004;75(1):27-34.

30. Hannema SE, van Duyvenvoorde HA, Premsler T, Yang RB, Mueller TD, Gassner B, et al. An activating mutation in the kinase homology domain of the natriuretic peptide receptor-2 causes extremely tall stature without skeletal deformities. J Clin Endocrinol Metab. 2013;98(12):E1988-98.

31. Hwang IT, Mizuno Y, Amano N, Lee HJ, Shim YS, Nam HK, et al. Role of NPR2 mutation in idiopathic short stature: Identification of two novel mutations. Mol Genet Genomic Med. 2020;8(3):e1146.

32. Asadollahi R, Zweier M, Gogoll L, Schiffmann R, Sticht $H$, Steindl $K$, et al. Genotype-phenotype evaluation of MED13L defects in the light of a novel truncating and a recurrent missense mutation. Eur J Med Genet. 2017;60(9):451-64.

33. Sato S, Tomomori-Sato C, Parmely TJ, Florens L, Zybailov B, Swanson SK, et al. A set of consensus mammalian mediator subunits identified by multidimensional protein identification technology. Mol Cell. 2004;14(5):685-91. 
34. Abdel-Salam GMH, Sayed ISM, Afifi HH, Abdel-Ghafar SF, Abouzaid MR, Ismail SI, et al. Microcephalic osteodysplastic primordial dwarfism type II: additional nine patients with implications on phenotype and genotype correlation. Am J Med Genet A. 2020;182(6):1407-20.

35. Rossi-Espagnet MC, Dentici ML, Pasquini L, Carducci C, Lucignani M, Longo D, et al. Microcephalic osteodysplastic primordial dwarfism type II and pachygyria: morphometric analysis in a 2-year-old girl. Am J Med Genet A. 2020;182(10):2372-6.

36. Muncke $\mathrm{N}$, Jung $\mathrm{C}$, Rüdiger $\mathrm{H}$, Ulmer $\mathrm{H}$, Roeth $\mathrm{R}$, Hubert $\mathrm{A}$, et al. Missense mutations and gene interruption in PROSIT240, a novel TRAP240-like gene, in patients with congenital heart defect (transposition of the great arteries). Circulation. 2003;108(23):2843-50.

37. Adegbola A, Musante L, Callewaert B, Maciel P, Hu H, Isidor B, et al. Redefining the MED13L syndrome. Eur J Hum Genet. 2015;23(10):1308-17.

38. Bober MB, Niiler T, Duker AL, Murray JE, Ketterer T, Harley ME, et al. Growth in individuals with Majewski osteodysplastic primordial dwarfism type II caused by pericentrin mutations. Am J Med Genet A. 2012;158A(11):2719-25.

39. Rauch A, Thiel CT, Schindler D, Wick U, Crow YJ, Ekici AB, et al. Mutations in the pericentrin (PCNT) gene cause primordial dwarfism. Science. 2008;319(5864):816-9.

40. Yin JW, Wang G. The Mediator complex: a master coordinator of transcription and cell lineage development. Development. 2014;141(5):977-87.

41. Huddleston J, Chaisson MJP, Steinberg KM, Warren W, Hoekzema K, Gordon $\mathrm{D}$, et al. Discovery and genotyping of structural variation from long read haploid genome sequence data. Genome Res. 2017;27(5):677-85.

42. Sedlazeck FJ, Lee H, Darby CA, Schatz MC. Piercing the dark matter: bioinformatics of long-range sequencing and mapping. Nat Rev Genet. 2018;19(6):329-46.
43. Seo JS, Rhie A, Kim J, Lee S, Sohn MH, Kim CU, et al. De novo assembly and phasing of a Korean human genome. Nature. 2016;538(7624):243-7.

44. Shi L, Guo Y, Dong C, Huddleston J, Yang H, Han X, et al. Long-read sequencing and de novo assembly of a Chinese genome. Nat Commun. 2016;7:12065.

45. Zhou G, Chen Y, Zhou L, Thirunavukkarasu K, Hecht J, Chitayat D, et al. CBFA1 mutation analysis and functional correlation with phenotypic variability in cleidocranial dysplasia. Hum Mol Genet. 1999;8(12):2311-6.

46. Fons C, Sempere A, Sanmartí FX, Arias A, Póo P, Pineda M, et al. Epilepsy spectrum in cerebral creatine transporter deficiency. Epilepsia. 2009;50(9):2168-70.

47. Vasques GA, Arnhold IJ, Jorge AA. Role of the natriuretic peptide system in normal growth and growth disorders. Horm Res Paediatr. 2014;82(4):222-9.

48. Louw JJ, Corveleyn A, Jia Y, Hens G, Gewillig M, Devriendt K. MEIS2 involvement in cardiac development, cleft palate, and intellectual disability. Am J Med Genet A. 2015;167A(5):1142-6.

49. Illumina Clinical Services Laboratory, Department of Clinical Services, 5200 Illumina Way San Diego, California, United States 92122. https:// www.ncbi.nlm.nih.gov/clinvar/variation/340486/.

50. Illumina Clinical Services Laboratory, Department of Clinical Services, 5200 Illumina Way San Diego, California, United States 92122. https:// www.ncbi.nlm.nih.gov/clinvar/variation/211882/.

\section{Publisher's Note}

Springer Nature remains neutral with regard to jurisdictional claims in published maps and institutional affiliations.
Ready to submit your research? Choose BMC and benefit from:

- fast, convenient online submission

- thorough peer review by experienced researchers in your field

- rapid publication on acceptance

- support for research data, including large and complex data types

- gold Open Access which fosters wider collaboration and increased citations

- maximum visibility for your research: over $100 \mathrm{M}$ website views per year

At BMC, research is always in progress.

Learn more biomedcentral.com/submissions 